\title{
Primates and \\ conservation priorities in Madagascar
}

\author{
Jon I. Pollock
}

Madagascar's conservation problems are many, but the Malagasy Government is working towards solutions, having recently passed into law a strategy that links development with the conservation of natural resources. The protection of the country's remaining forests is a key concern, both for the human population and for the non-human primates. The author is a primatologist and has a research background in behavioural ecology, reproduction and conservation, especially with prosimians. This article was first presented at the joint Primate Society of Great Britain/ FFPS meeting on primate conservation in December 1985.

It is impossible to appreciate the depth of Madagascar's conservation problems without a brief discussion of the base economy, population structure and life style of the people. In this paper I present some background information on the crisis in Madagascar and follow this with an assessment of the forestry situation and its implications for primate conservation. I am adopting a sociological and economic approach because Madagascar has recently passed into law a national strategy that formally links development with the conservation of natural resources. It is appropriate to consider primates specifically because they are indicators of ecological health and because, for the most part, they depend entirely on trees. Erosion, mineral depletion, watershed loss and the fuelwood emergency in Madagascar have their origins in deforestation, and trees can be seen as the focus of competition between people and primates. Consequently their protection will be the saviour of both.

\section{Human activity}

The history of human settlement in Madagascar is poorly understood, but sea traders and fishing communities certainly occupied coastal regions long before the high central plateaux were first colonized sometime in the first 500 years $\mathrm{AD}$. It is probable that forest cover in the central regions was not complete, and that edaphic grasslands formed a mosaic with tracts of forest of varying size and density (Dewar, 1984). The grasslands were probably dotted with trees and clumps of trees, which permitted arboreal lemurs like Paleopropithecus to coexist with giant terrestrial ratites such as the roc Aepyomis maximus. Presumably it was grazing competition with cattle, direct predation, and fire that accounted for the disappearance of some 20 species of primate, the roc and the hippopotamus as tree cover decreased and the human population grew.

Today there are about 9 million people with an annual growth rate of 2.7-3.1 per cent, which corresponds to a doubling of the population in 22-26 years. Approximately one-half of the inhabitants are under the age of 20 (Thompson, 1982). The population is mostly rural. In 197286 per cent lived in villages of fewer than 2000 people and only 8 per cent in towns of more than 20,000 people. There are only six towns with more than 30,000 inhabitants and four of these are coastal ports. Approximately 85 per cent of the people are agriculturalists, pastoralists or a combination of the two (Battistini and Verin, 1972). The overall population density of 15 per $\mathrm{sq} \mathrm{km}$ can rise to over 50 individuals per sq $\mathrm{km}$ locally (outside towns), particularly in the east 
surrounding the remaining tracts of evergreen rain forest (Figure 1).

There has been virtually no significant industrialization in Madagascar, largely because of the poor availability of large mineral deposits. Sources of chromite, mica, graphite and iron are sufficient only for local use and for a little raw product export as a source of foreign revenue. Poor utilizable energy reserves are another impediment to industrialization; oil and gas are being sought, both on- and off-shore, but small manufacturing plants commonly use wood and charcoal as their main energy source.

The agricultural economy is dominated by the cultivation of rice for personal consumption. Each Malagasy consumes about $500 \mathrm{~g}$ of rice each day, and 95 per cent of the 2 million tonnes produced yearly is retained for domestic use. Since 1972 Madagascar has been a net importer of rice, spending 8.5 per cent of its foreign income on this (FAO, 1981). Rice is grown wherever there is sufficient water, with concentrations around larger towns and in the 'bread-basket' areas of Lake Alaotra and Fianarantsoa. The rice paddies in these regions, which require a permanent drainage channel for constant irrigation, are the most productive in the land and account for 85 per cent of overall rice production.

Although hill-grown rice or 'tavy' constitutes only 15 per cent of national rice production, it can form a much greater proportion locally, especially in the mountainous parts of the east. It is in these areas of high population density that some of the richest rain forests in the world are being slowly destroyed. Area-richness index estimates for these forests (IUCN-CMC, 1985; Lebrun, 1960) reveal them to be equal or superior in plant species diversity to the Cape Province of South Africa, generally acknowledged to be the highest in the world. (Estimates of the actual number of plant species in Madagascar vary between 8000 and 12,000 (IUCN-CMC, 1985) with 90 per cent species endemism). Hill rice cultivation has been estimated as causing permanent deforestation of 10,000-15,000 hectares per year (DeLord, 1965), although other reports put this figure as high as 50,000 ha per year. The forest is 'slashed-and-burnt', cultivated for one or two years, and then left fallow as the farmer moves on. Economic pressure to increase rice production has reduced the traditional fallow rotation period from $10-15$ years to intervals as short as two years. This has resulted in serious chemical depletion of the soil, which prevents forest regeneration and creates a direct primary-forest-tosavannah route of degradation, which appears to be permanent. Hill rice farming generally produces low yields $-600 \mathrm{~kg}-1$ tonne per ha-and paddy rice is normally twice as successful (Oxby, 1985). However, farmers persist in hill rice cultivation for the following reasons (Ratovoson, 1979): the rice itself is more palatable; its less specialized cultivation technique permits mixed planting with maize, manioc and beans; the wood from clearing operations can be used for fuel and construction; it requires no terracing; no offseason maintenance is needed; it establishes

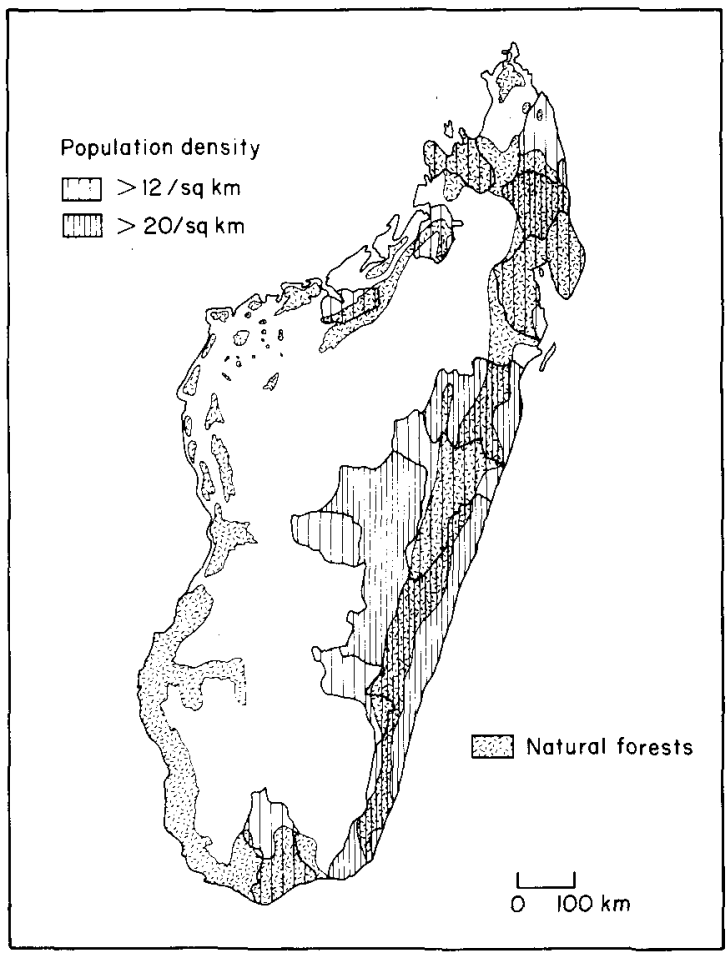

Figure 1. Regional variation of population density in Madagascar with approximate distribution patterns of the remaining natural forests. Demographic patterns adapted from the FTM 1:6,000,000 map (1984); forest cover adapted from the FTM $1: 2,000,000$ map 9th edition (1984). [FTM = Foiben-Taosarintanin'I Madagasikara (Malagasy for the French equivalent of Institut National de Geodesie et. Cartographie).] 
tenure on public land; and it is a private system, which avoids administrative control, pressures and, probably, taxes as it takes place away from administrative centres and lines of communication.

It is clear that forest protection measures in eastern Madagascar must take into account the economic realities behind hill rice cultivation and should support alternative activities that preclude forest destruction and that are acceptable to farmers. As in West Africa, the conservation crisis has much to do with a mobile population exploiting scattered or temporary resources. The ecological problems of both pastoralism and shifting cultivation require sympathetic but firm government action in order to achieve environmental stability.

The second major environmental pressure in Madagascar concerns the fuel supply. Very few quantitative data are available with which to analyse exploitation of natural forests for fuel, but in $19802,520,000$ tonnes of firewood and 71,000 tonnes of charcoal were produced to supply 95 per cent of Madagascar's energy needs (Eaux et Forêts, 1980). These figures represent approximately $4,200,000 \mathrm{cu} \mathrm{m}$ of dry wood (FAO, 1978; Gorse, 1985), which is equivalent to $200,000-400,000$ ha of natural forest, depending on the region. This would be equivalent to $1-3$ per cent of the remaining forest cover destroyed annually. In the east and the high plateau regions much fuel wood is derived from regrowth and plantations, but the situation in the south and west is quite different. It is extraordinary to see even the bizarre and doubtfullooking Alluaudia forests of the south now being severely exploited for charcoal.

The annual burning of the grasslands, especially in the unproductive and highly eroded high plateau, to stimulate fodder growth for cattle has probably accounted, in large measure, for forest destruction in this region. So little upland forest now remains in this area that, apart from the risk to plantations, burning only has a detrimental effect on soil fertility and erosion. Soil conservation is an increasing problem of enormous proportions. It has been estimated that in the Betsiboka catchment area soil is lost at a rate of 1600 tonnes per sq $\mathrm{km}$ per year, equivalent to
$2 \mathrm{~mm}$ topsoil over an area of $60,000 \mathrm{sq} \mathrm{km}$ (Le Bourdiec, 1972).

In the west it has been estimated that some 2000 ha of forest are inadvertently burnt through grass firings each year. The policy of the Malagasy Government on burning by farmers seems to be ambiguous: it is officially condemned, but tolerated in practice. 'Operation Danga', inaugurated a few years ago to reduce fires, largely through educational programmes, achieved initial success, but fires resulting from vandalism and political action-especially in and around plantations-have recently been increasing.

Finally, forest exploitation for commercial gain has influenced forest structure in many parts of Madagascar and has been responsible for clearfelling in others. In general, however, it has occurred near the main transport routes, which are very limited, and has not invaded the significant forest blocks. Most clear-felled areas have been replanted and managed as forestry stations. The southern forests are of little commercial value for this purpose, being dominated by fleshy rather than woody plant forms, and the poor productivity of the western forests (about 10 $\mathrm{cu} \mathrm{m}$ per ha) makes classical methods uneconomical. In the east, inaccessibility, mountainous terrain and the preponderance of small trees, often with poor straight-wood characteristics, also limit further rational commercial utilization. Traditional felling and preparation methods are slow and inefficient, and unworked timber can no longer be exported from Madagascar by law. There is no doubt, however, that the single most important protection effect on Madagascar's forests has been the limited, poorly maintained and seasonally inactive road system. Where the terrain and access have permitted it, forest destruction has been dramatic, resulting, for example, in the 90 per cent loss of coastal evergreen forest in the east.

\section{Protected areas}

Reappraisal of the nature protection system in Madagascar must start with an examination of the extensive existing reserve network. This consists of 35 Nature Reserves, Special Reserves and National Parks totalling $9410 \mathrm{sq} \mathrm{km} \mathrm{(1.6} \mathrm{per} \mathrm{cent}$ of the surface area on the island) and well 
distributed across the different vegetational and climatic zones (Figure 2). In addition, there is an array of Forest Reserves and Classified Forests affording limited protection, but covering a total area of $45,626 \mathrm{sq} \mathrm{km}$ (7.7 per cent of Madagascar's surface area). In general the reserve network receives adequate legislative support, although enforcement is heavily compromised by poor staffing levels and transportation problems. At present the responsibility for protection of all reserves and for the enormous problem of soil conservation is carried out by one office in a junior department of one ministry. Over 60 per cent of the budget of this department is spent supporting plantation management, and the total material support budget for the reserve network is $\$ 1100$ per annum. In every reserve I have visited the forestry agent responsible for administrating protective measures either has been unable to visit the reserve regularly, or cannot adequately survey it, for lack of transport. Reserve wardens are knowledgeable and interested in their forests, but too many are elderly with family commitments that compromise their ability and motivation to undertake foot-patrols in remote areas. An internal reassessment of the priority placed on the Conservation Office's endeavours-perhaps with non-governmental financial support-is urgently needed. This must include programmes of training in conservation science for wardens and the provision of more money for rangers and equipment. High priorities in this area are the means to delimit physically the reserves' boundaries, to clear paths and to distribute the training and equipment required to survey and map the areas accurately, followed by inventories of the fauna and flora. It is an astonishing fact that not even a complete list of the biological components exists for any protected area in

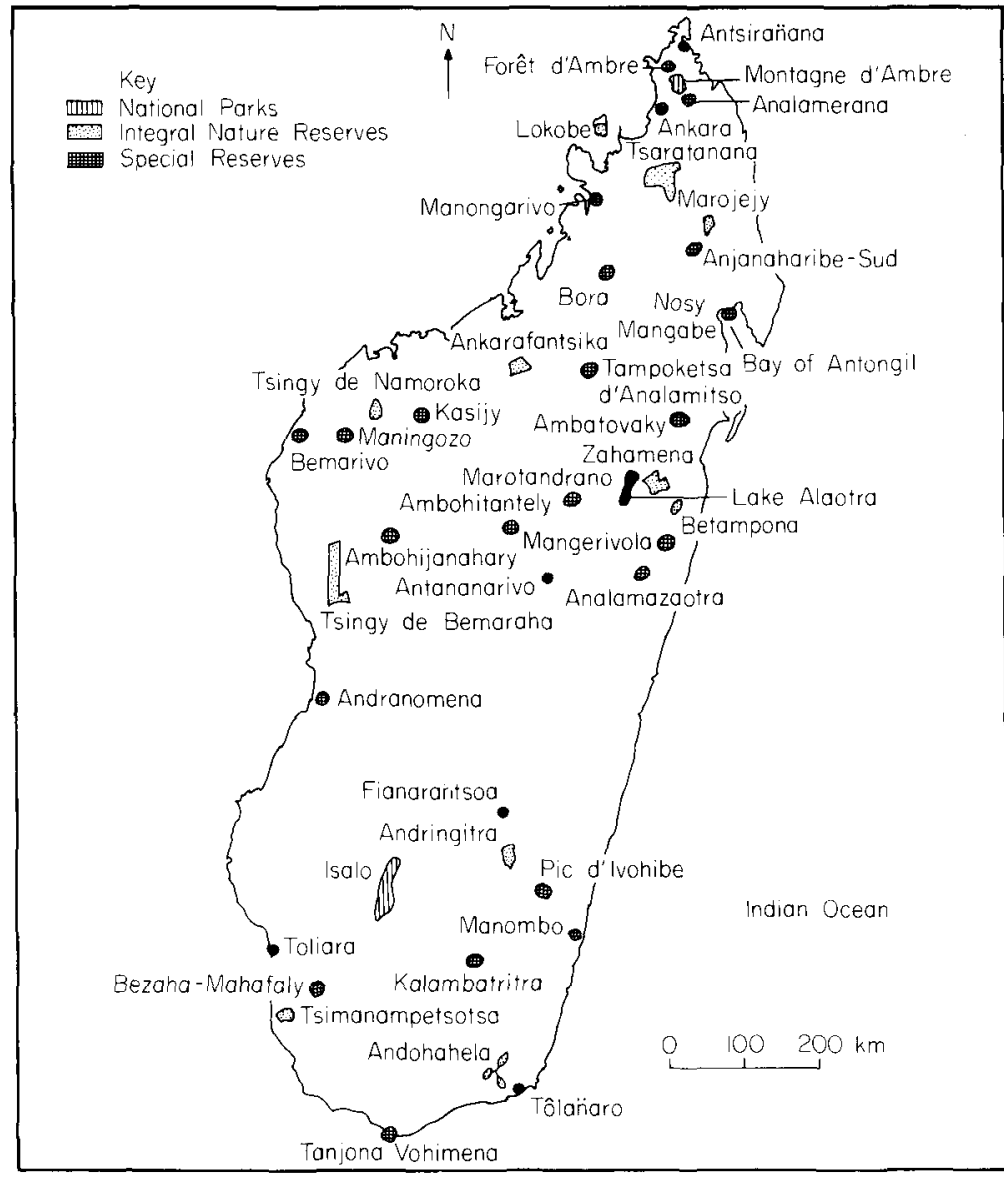

212
Right: The edge of the second 'parcelle' of the Andohahela Nature Reserve at Hazafotsy showing an example of classical Didieraceae 'spiny forest' (Jon I. Pollock).

Figure 2. The location of the network of principal national parks and nature reserves in Madagascar (adapted from IUCN-CMC, 1985).

Oryx Vol 20 No 4, October 1986 


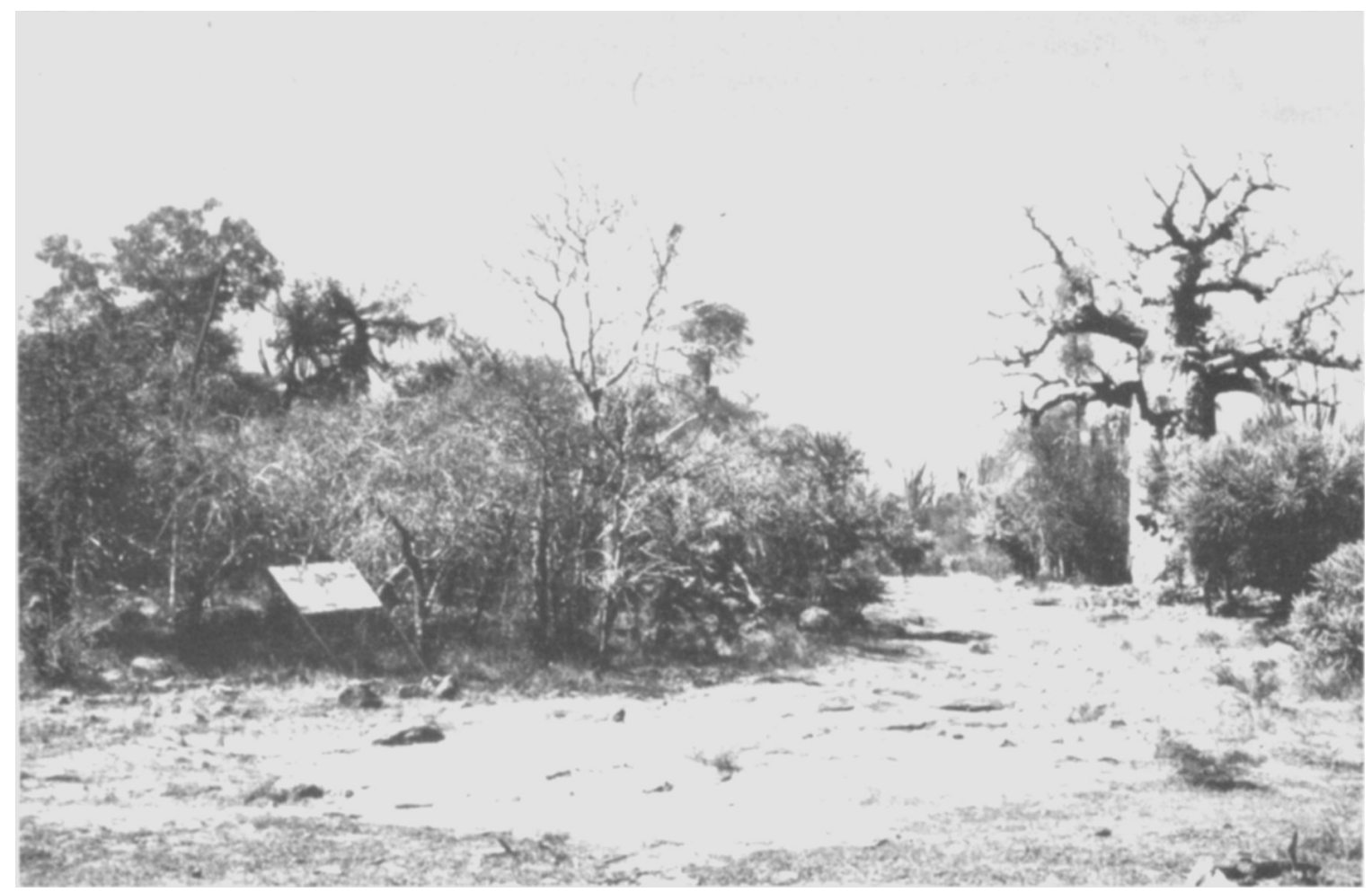

Madagascar. A top priority is the preparation of ecosystem-orientated management plans for each major reserve based on data obtained in the surveys.

A second fundamental problem is reserve size. Much theoretical and practical research has shown that, over the long term, large reserve size is a critical factor in slowing the rate of species extinctions (Frankel and Soulé, 1981). The smallest official reserve in Madagascar is 520 ha, but no fewer than 14 are less than 10,000 ha, and one-half of the reserves in the east are less than 10,000 ha. Although the largest number of reserves is to be found in the eastern region, their average surface area $(23,300 \mathrm{ha})$ is the lowest of all the regions (south $=27,560$ ha; west $=27,190$ ha; north $=30,070$ ha). The east is intermediary in the percentage of remaining forest cover that exists in protected areas (south $=3.8$ per cent, east $=6.1$ per cent and west $=11.7$ per cent with the south and its exceptionally high plant species endemism of 95 per cent now in a critical situation). The existing Primates and conservation in Madagascar reserve network, therefore, consists of an adequate number of protected areas covering the main terrestrial zones but, given the diversity of flora and fauna, the total coverage is inadequate and there are too many reserves too small in size. One of the main consequences of this problem is the heavy drain on resources that the administration and management of many small protected areas incurs.

The problems faced by the present adminstration preclude the establishment and adequate maintenance of many new reserves but, together with international organizations, a way must be found to increase reserve size in priority areas and to fill two large gaps in the reserve network: the Didierea/Alluaudia/Euphorbia forest formations of the extreme south, and a substantial block of eastern rain forest that includes coastal or lowaltitude areas. At present the former are protected only in the 500-ha Bezaha-Mahafaly Special Reserve inaugurated in November 1985, in one part of the poorly protected Andohahela Nature Reserve, and in the limestone sector of the 
Tsimanampetsotsa Nature Reserve on the Mahafaly massif. There are plans to extend the Bezaha-Mahafaly Special Reserve by 500 ha in an area where damage by goats threatens the spiny forest. The Andohahela sector covered an area of 12,900 hectares in 1966 , but protection has not been enforced and there has been exploitation of the reserve, at least for fuelwood. In all, therefore, this uniquely structured xerophytic vegetation with generic and specific endemism of 48 and 95 per cent respectively. which is physically dominated by the endemic family Didiereacae, and has seven species of baobab, is protected in areas totalling only about 50,000 ha. In addition to a forest management plan for the whole of the southern province of Toliara, a strong case can therefore be made to encourage the authorities to create a special reserve of at least 100,000 ha in the Mahafaly or Karimbola region of the extreme south.

In the east, $55-60,000 \mathrm{sq} \mathrm{km}$ of lowland rain forest, about one-tenth of Madagascar's surface area, once lined the coast for $50 \mathrm{~km}$ or so inland. It has been almost completely destroyed; only offical reserves of $77.7 \mathrm{sq} \mathrm{km}$ (approximately 0.1 per cent of the former area) are protected by law. The eastern coastal flora is amongst the most diverse in the world, Perrier de la Bathie (1921) recording 102 species of woody plant in $100 \mathrm{sq} \mathrm{m}$ near Maroantsetra in the north-east. Recent sampling has also revealed decremental changes in species diversity with altitude, and very high tree densities and species abundance in these forests (Pollock, 1986). The fauna is correspondingly rich, with more vertebrate and invertebrate species of each class represented than in any other part of the island (Paulian 1961). There are only four reserves of over 50,000 hectares in eastern Madagascar, and none includes the coastal series (Myristicaceae and Anthostema) of vegetation type that grows below $800 \mathrm{~m}$. Of these four, one has been subject to severe hunting pressure (Marojejy), one is poorly protected (Andohahela), and one has a core area made up by a legal, but rapidly increasing human settlement (Zahamena). The remaining reserve (Ambatovaky) is an unknown quantity until surveys are made, but is likely to be of great importance. The only area where a large forest tract exists, which extends from highlands down to the sea and is not subject to immediate population pressure, is the Makira to Antsiatsia forest block west of the Bay of Antongil. This area owes its protection to the poor communication lines it has in all directions. It is also perhaps the richest area as far as faunal diversity is concerned, according to the little information there is available. A natural reserve with full protective status, preferably of at least 250,000 ha, should be urgently considered for this area. So as not to withdraw resources from the existing network at this critical stage, the immediate need here is primarily for legislation and definition of the limits of the reserve.

\section{Primates}

Because of the close dependency of all Malagasy primates on trees, the problems of primate conservation in Madagascar are largely the same as those of forest conservation. The Malagasy primates, together with their predators, are the largest of the island's mammalian fauna, and experience the slowest growth rates and reproductive output. They are, therefore, most sensitive to environmental disturbance and probably respond least successfully to population crashes.

This means that of all the Malagasy fauna, the lemurs must be protected in areas sufficiently large to maintain substantial population sizes. One popular criterion for the minimum population size sufficient to maintain most of the genetic diversity requires there to be at least 500 individuals of immediate breeding capability in a wild population. To achieve this, the largest lemur, Indri indri, would probably have to exist in a population of at least 1000 individuals, which at an observed density of about 10 individuals per $\mathrm{sq} \mathrm{km}$, would require a reserve of 10,000 hectares. It is chastening to realize that Analamazoatra Special Reserve, which was created for this species, covers just 800 ha. Furthermore, the reserve established in 1966 for the aye-aye Daubentonia madagascariensis on the island of Nosy Mangabe covers only 520 ha, which can probably only maintain a population size one order of magnitude lower than the theoretical requirement. It appears, therefore, that the future for some Malagasy primates will depend on the careful ecological administration 
of their habitat and their populations. This will require scientific information on basic ecology and population dynamics, which is not yet available for the majority of species.

It should be mentioned here that 10 of the 20 species of primate on Madagascar weigh $1 \mathrm{~kg}$ or less. The smallest. Microcebus, weighs as little as $60 \mathrm{~g}$ and lives at population densities of up to 2600 individuals per sq $\mathrm{km}$. They can be found successfully exploiting secondary growths and even bushy vegetation at an early stage of forest regeneration. (Recolonization of regrowths is in itself a subject worthy of intensive scientific research in Madagascar.) My comments are, therefore, biased towards the most threatened primates, which are generally the largest and which live in the east.

Reserves are not the only areas where primates still exist in Madagascar. I do not think that the population sizes of any species within protected areas are superior to those outside them. Many reserves are still linked genetically with adjacent or nearby forest blocks experiencing varying levels of disturbance, and policy decisions are badly needed to maintain these essential relationships. Primate migration, however, is slow and the dangers of forest fragmentation are becoming increasingly apparent. In the north-west of Madagascar, for example, the problem is particularly acute, most of the forest patches existing in the late 1950s being less than a few hundred hectares in size. Forest fragmentation effects are, however, also acute in the east because primate species diversity is higher and abundance lower in this region (Pollock, 1986). The biomass estimates for the eight leaf-eating primates at Analamazoatra (4.6-5.8 kg per ha, Pollock, 1975) are much lower than those for the four comparable species at Antserananomby in the west (58-74 kg per ha, Sussman, 1972). However, most reported lemur population densities in the west can be reliably regarded as maximum values, research in this region having concentrated on rich gallery forests rather than the more prevalent xerophytic 'bush'.

Hunting pressure on primates in Madagascar has never been assessed, and it would be extremely difficult to do so as it is illegal. I believe that it might be a significant factor in small forest patches of easy access such as Nature Reserve No. 1 at Betampona, and for species such as Varecia variegata, which exhibits suicidal non-fleeing behavioural responses. Dense forests, cryptic coloration and nocturnal habits certainly afford some protection. More commonly, baited traps are set, usually near forest edges, where the forest is being worked for wood or some other resource. By their frequency it is likely that these endeavours meet with some success, but their effect on lemur populations is quite unknown.

Some species, especially Indri indri, are 'fady', meaning that it is taboo to harm or eat them. For the aye-aye, however, the 'fady' acts detrimentally because the danger in looking directly at the animal's face is seen by many as worse than the penalty of killing it, and they are generally stoned on sight. It is probable that in accessible parts of its range this belief has had a locally significant effect on population size, but it is unlikely to be as important as forest destruction in the same area.

\section{Conclusion}

The action required to begin a rationalization of primate and forest conservation in Madagascar has three perspectives (Table 1). Firstly, the Malagasy Government should be encouraged to increase the power of the Conservation Office by increasing political and financial support. Serious consideration should, I believe, be given to its elevation to a separate department, especially if soil conservation responsibilities are to remain a forestry issue. This change would have rebound effects on the quality of administrators in office and the training they receive. It would also eventually lead to a more widespread awareness in the country of the role Madagascar's biological uniqueness can play in its national heritage. A review of protected area legislation is required, especially with respect to (a) the protection of existing forests surrounding and near to reserves; (b) reforming reserve boundaries with respect to the activity and needs of local people; and (c) the proposal to consider creating two new reserves. The government also has a significant role to play in ensuring that the Commission set up to implement the National Conservation Strategy, and its Technical Committee, function smoothly 
Table 1. Primate conservation priorities in Madagascar

A. Government action

1. Increased support, status and budget for the Conservation Office

2. Review of protected area legislation

3. Effecting an efficient implementation procedure for the work of the newly formed Commission on the National Conservation Strategy

B. Intemational organizations

1. Co-ordination of objectives with those of the National Strategy.

2. Creation of joint projects that link protected area management with local economic needs - especially in relation to rice cultivation and fuelwood provision

C. Immediate field action

1. Preparation of a vegetation and land-use map from recent satellite imagery

2. Extensive foot and aerial surveys of each reserve followed by detailed biological inventory research and the creation of individual management plans

3. Establishing local people in economically realistic projects based on the principles of forest protection and reserve maintenance

and quickly to enable progress to be made.

Secondly, a large measure of responsibility for Madagascar's conservation programme rests on the international organizations, which, in recognizing its global importance and focus on development, will provide the funds required. They will also need to co-ordinate their objectives in the framework of jointly funded and administered field projects. Ways must be found to link nature reserve and species conservation programmes with the economic needs of villagers, especially in relation to rice cultivation and fuelwood provision.

Finally, the field action initially required should include projects that result in up-to-date vegetation and land-use maps of Madagascar, individual reserve management plans based on detailed survey and inventory work, and substantial involvement by local people in maintaining and protecting the reserves and other forests in their administrative areas.

\section{References}

Battistini, R. and Verin, P. 1972. Man and the environment in Madagascar. In Biogeography and Ecology in Madagascar (Eds R. Battistini and G. Richard-Vindard. pp. 311-338. Monographice Biologicae 21. Junk, The Hague.

DeLord, J.M. 1965. Monographie de la Côte Est de Madagascar. Bulletin Technique des Eaux et Forêts et de la Conservation des Sols, 2.

Dewar, R. 1984. Extinctions in Madagascar: the cases of the 216
Martin and R. G. Klein). pp. 574-593. University of Arizona Press.

Eaux et Forêts. 1980. Report quoted in IUCN - CMC (1985).

FAO 1978. Yearbook of Forest Products 1966-1976. FAO. Rome.

FAO 1981. Production Yearbook 1980. FAO. Rome.

Frankel, O.H. and Soulé. M.E. 1981. Conservation and Evolution. Cambridge University Press. Cambridge.

Gorse, J. 1985. Fuelwood and domestic energy: the fuelwood 'crisis' in tropical west Africa. World Bank Report.

IUCN-CMC. 1985. An Environmental Profile of Madagascar. Conservation Monitoring Centre. Cambridge.

Le Bourdiec, P. 1972. Accelerated erosion and soil degradation. In Biogeography and Ecology in Madagascar (Eds R. Battistini and G. Richard-Vindard). pp. 227-260. Monographiae Biologicae 21. Junk. The Hague.

Lebrun, J. 1960. Sur la richesse de la flore de diverses temtoires Africaines. Bulletin des Séances de l'Academie Royal des Sciences Outre-Mer. n. s. 6(2), 669-690.

Oxby, C. 1985. Forest farmers: the transformation of land use and society in eastern Madagascar. Unasylua 37 (148). $42-51$.

Paulian. R. 1961. La Zoogeographie de Madagascar et des îles voisines. Faune de Madagascar XIII. IRS. Tananarive.

Perrier de la Bathie. M.H. 1921. La vegetation malgache. Annales de Musée Colonial de Marseille serie 3. vol. 9.

Pollock. J.I. 1975. The Social Behaviour and Ecology of Indri indri. PhD Thesis. University of London.

Pollock. J.I. 1986. Towards a conservation policy in eastern Madagascar Primate Conservation (in press).

Ratovoson. C. 1979. Les problèmes du tavy sur la côte est malgache. Madagascar Revue de Geographie. 35, $141-$ 163.

Sussman. R.W. 1972. An ecological study of two Madagascan primates: Lemur fuluus rufus (Audebert) and Lemur catta (Linnaeus). PhD Thesis. Duke University. North Carolina.

Thompson. V. 1982. Madagascar. In Africa South of the Sahara. Europa Press.

Jon I. Pollock, 25 Florence Park. Westbury Park. Bristol BS6 7LS. UK.

Oryx Vol 20 No 4. October 1986 